\title{
Von Willebrand Disease, Type 2M
}

National Cancer Institute

\section{Source}

National Cancer Institute. von Willebrand Disease, Type 2M. NCI Thesaurus. Code C131688.

An autosomally inherited (generally dominant) coagulation disorder characterized by qualitative abnormalities of the von Willebrand factor (VWF). The mutant VWF shows decreased platelet adhesion without a deficiency of high molecular weight multimers; this functional defect is caused by mutations that disrupt VWF binding to platelets or to subendothelium. 